Marquette University

e-Publications@Marquette

School of Dentistry Faculty Research and

Publications

Dentistry, School of

$9-2020$

\title{
Magnetic Dual-Template Molecularly Imprinted Polymer Based on Syringe-To-Syringe Magnetic Solid-Phase Microextraction for Selective Enrichment Of P-Coumaric Acid and Ferulic Acid from Pomegranate, Grape, And Orange Samples
}

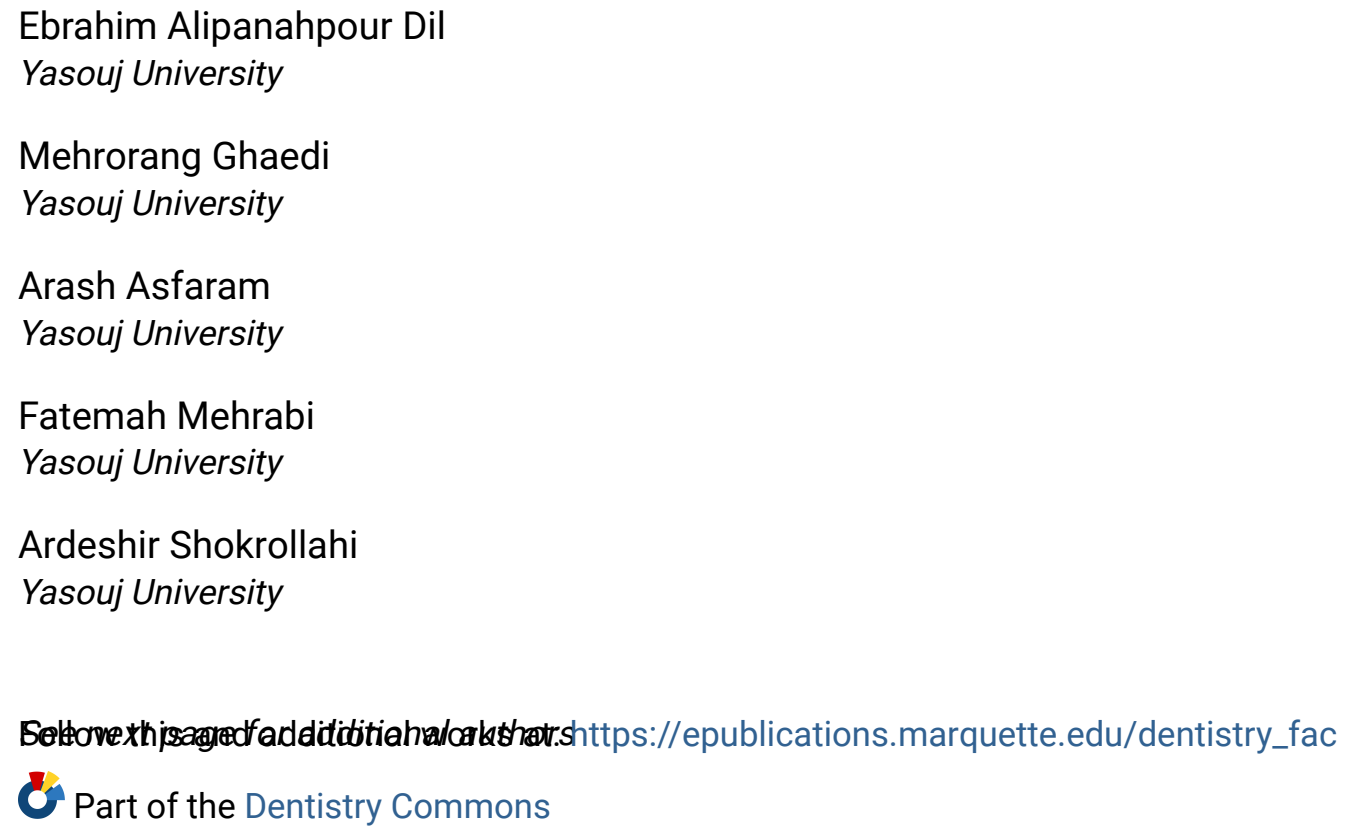




\section{Authors}

Ebrahim Alipanahpour Dil, Mehrorang Ghaedi, Arash Asfaram, Fatemah Mehrabi, Ardeshir Shokrollahi, Amir Abbas Matin, and Lobat Tayebi 
Marquette University

e-Publications@Marquette

\section{Dentistry Faculty Research and Publications/School of Dentistry}

This paper is NOT THE PUBLISHED VERSION.

Access the published version via the link in the citation below.

Food Chemistry, Vol. 325 (September 2020): 126902. DOI. This article is (C) Elsevier and permission has been granted for this version to appear in e-Publications@Marquette. Elsevier does not grant permission for this article to be further copied/distributed or hosted elsewhere without express permission from Elsevier.

\section{Magnetic Dual-Template Molecularly Imprinted Polymer Based on Syringe-To-} Syringe Magnetic Solid-Phase Microextraction for Selective Enrichment Of P-Coumaric Acid and Ferulic Acid from Pomegranate, Grape, And Orange Samples

Ebrahim Alipanahpour Dil

Department of Chemistry, Yasouj University, Yasouj 75918-74831, Iran

Mehrorang Ghaedi

Department of Chemistry, Yasouj University, Yasouj 75918-74831, Iran

Arash Asfaram

Medicinal Plants Research Center, Yasuj University of Medical Sciences, Yasuj, Iran

Fatemeh Mehrabi

Department of Chemistry, Yasouj University, Yasouj 75918-74831, Iran 


\title{
Ardeshir Shokrollahi
}

Department of Chemistry, Yasouj University, Yasouj 75918-74831, Iran

\section{Amir Abbas Matin}

Department of Chemistry, Faculty of Basic Sciences, Azarbaijan Shahid Madani University, Tabriz, Iran Lobat Tayebi

Marquette University School of Dentistry, Milwaukee, WI

\begin{abstract}
Magnetic dual-template molecularly imprinted polymer $\left(\mathrm{Fe}_{3} \mathrm{O}_{4} @ \mathrm{SiO}_{2}-\mathrm{MDMIP}\right)$ was prepared to enrich and determine both $p$-Coumaric acid ( $p-C A$ ) and ferulic acid (FA) based on syringe-to-syringe magnetic solid-phase microextraction (SS-MSPME). The obtained MDMIP was characterized and recognized, and then its adsorbing performance was studied. Based on the results, the $\mathrm{Fe}_{3} \mathrm{O}_{4} @ \mathrm{SiO}_{2}-\mathrm{MDMIP}$ indicated selective recognition towards $\mathrm{p}-\mathrm{CA}$ and FA with large adsorption capacity. The optimization of MDMIPSS-MSPME conditions ( $\mathrm{pH}, \mathrm{Fe}_{3} \mathrm{O}_{4} @ \mathrm{SiO}_{2}-\mathrm{MDMIP}$ mass, $\mathrm{NaCl}$ concentration, number of cycle, and elution volume) were conducted using the central composite design (CCD). Under the optimum conditions, an effectual and a convenient method was established to determine p-CA and FA in pomegranate, grapes, and orange samples based on SS-MSPME coupling with high-performance liquid chromatographyultraviolet (HPLC-UV). Our developed method showed the limit of detection (LOD) of $0.08 \mathrm{ng} \mathrm{mL}^{-1}$ for $\mathrm{p}-\mathrm{CA}$ and $0.07 \mathrm{ng} \mathrm{mL}^{-1}$ for FA. The method also indicated good linearity with $\mathrm{R}^{2}>0.99$ and good recoveries of $85.12-94.96 \%$ with RSDs $\leq 5.58 \%$ spiked at three various concentration levels in pomegranate, grapes, and orange samples.
\end{abstract}

\section{Keywords}

Magnetic molecularly imprinted polymer, p-Coumaric acid and ferulic acid, Selective enrichment, Magnetic solid phase microextraction, Fruits samples

\section{Introduction}

p-Coumaric acid ( $p-C A$ ) and ferulic acid (FA) are two known organic compounds found abundantly in fruits. By virtue of antimicrobial, antioxidant, antineoplastic, anti-inflammatory, anti-Alzheimer, and antimutagen effects, along with the UV protection and neuroprotective impacts, $\mathrm{p}$-CA and FA are suitable for industrial applications, particularly in food, pharmaceutical, chemical and cosmetics industries. In view of this, great attention and attempts are required to design analytical methods for sensitive, precise and rapid determination of the two mentioned compounds in real samples (Khezeli et al., 2016, Long et al., 2019).

Analytical apparatuses used for $\mathrm{p}-\mathrm{CA}$ and FA determination in real samples must guarantee that they are more accurate, sensitive, rapid, and convenient than traditional and earlier methods. The measurement of any analyte with high precision and accuracy in real samples is the goal of numerous researchers. This goal, however, cannot be achieved unless the following limitations are resolved:

(i) A variety of analytes do not allow for their direct quantification; therefore, there is a need for preliminary derivation. 
(ii) Many real samples cannot directly be delivered to an instrument due to their physical state and their matrices, in terms of complexity and unknown situation.

(iii) Interfering species level strongly varies with various magnitude, depending on their level of effect on the determination of analytes.

(iv) The low level of analytes in real samples calls for conducting a preliminary preconcentration step and applying a high-sensitivity approach and/or instrument.

Recognition and simplification of a sample matrix and monitoring interfering species are mainly costly and laborious and require a large amount of real sample and the consumption of reagents (Dil et al., 2019, Ghorbani et al., 2019). Interference of a sample matrix, together with the preconcentration of target compounds leads to the final outcome of repeatability and the accurate determination of target analytes (Huang et al., 2020). Solid-phase microextraction (SPME), liquid-liquid extraction (LLE), magnetic solid-phase extraction (MSPE), solid-phase extraction (SPE), liquid-liquid microextraction (LLME) are a number of methods have hitherto been suggested for the preconcentration of analytes from various samples (Dil et al., 2019, Dil et al., 2020, Moradi et al., 2019, Pang et al., 2019).

Owing to the miniaturized scale, acceptable sensitivity, and reasonable accuracy and performance, SPME has highly been recommended for the preconcentration and microextraction of a wide range of varied analytes (Rahimi, Bahar, Heydari, \& Amininasab, 2019). This approach also benefits from ability to be automated, versatile, cheap, eco-friendly, selective, and sensitive, which dictates SPME success in enormous applications (Costa, Albergamo, Arrigo, Gentile, \& Dugo, 2019). Therefore, it is urgent to improve a selective, an effective and a practicable material for using in the SPME method. Construction of SPME configuration equipped with a highly selective trapping agent is the best strategy to enhance the characteristic performance of the aforesaid method.

Today, molecular imprinting technique (MIT) has been introduced as a perfect and notable synthetic method for the production of polymeric matrices, including specific recognition sites with high selectivity and affinity toward analyte. MIT has also been recognized as the most promising approach contributing to the introduction of molecular-specific recognition sites into a polymer matrix (Cheng et al., 2019). Molecularly imprinted polymers (MIPs) are potent materials that provide acceptable selectivity when cooperating with size and functional groups. The functionalities, shape, and size of MIPs are complementary to analyte and exhibit exceptional characteristic performance, including sensitivity, high selectivity, and capacity (Rozaini et al., 2019).

The present investigation reports a novel MDMIP for simultaneous preconcentration and determination of $\mathrm{p}-\mathrm{CA}$ and $\mathrm{FA}$ in fruits samples (including pomegranate, grape, and orange) in syringeto-syringe magnetic solid-phase microextraction (SS-MSPME) configuration. Effectual factors in the extraction recoveries of both compounds were optimized by central composite design (CCD), and HPLC-UV was applied to accurately and repeatedly monitor the compounds in real samples. 


\section{Materials and methods}

\subsection{Chemicals, apparatus, and HPLC conditions}

Applied chemicals, reagents, apparatuses, and HPLC conditions are reported in the Supplementary document.

\subsection{Synthesis of $\mathrm{Fe}_{3} \mathrm{O}_{4} @ \mathrm{SiO}_{2}-\mathrm{MDMIP}$ and $\mathrm{Fe}_{3} \mathrm{O}_{4} @ \mathrm{SiO}_{2}-\mathrm{MNIP}$ (magnetic non-molecularly imprinted polymer) nanoparticles}

Initially, $150 \mathrm{~mL}$ of aqueous solutions of $\mathrm{FeCl}_{3} \cdot 6 \mathrm{H}_{2} \mathrm{O}$ and $\mathrm{FeCl}_{2} \cdot 4 \mathrm{H}_{2} \mathrm{O}(1.1 \mathrm{~g}$ and $0.4 \mathrm{~g}$, respectively) in the molar ratio of $2: 1$ was preserved at $60{ }^{\circ} \mathrm{C}$ for $15 \mathrm{~min}$. After vigorous stirring and in the presence of $\mathrm{N}_{2}$ atmosphere, ammonium hydroxide solution (20 $\mathrm{mL} \mathrm{NH}{ }_{4} \mathrm{OH}$ [25\%]) was added to adjust to $\mathrm{pH} \sim 11$. This action led to the formation of a black suspension, which was maintained under vigorous stirring and $\mathrm{N}_{2}$ gas at $50^{\circ} \mathrm{C}$ for $2 \mathrm{~h}$. $\mathrm{Fe}_{3} \mathrm{O}_{4}$ magnetic nanoparticles were easily separated via a magnet, washed with double deionized water, and dried in a vacuum oven overnight (Nosrati, Sefidi, Sharafi, Danafar, \& Manjili, 2018). Subsequently, the MDMIP and MNIP were prepared as follows: $10 \mathrm{mg}$ of each of $\mathrm{p}-\mathrm{CA}$ and FA and $1.0 \mathrm{~mL}$ of (3-Aminopropyl) triethoxysilane were dissolved in $10 \mathrm{~mL}$ of methanol and stored at room temperature for $4 \mathrm{~h}$ (solution $\mathrm{A}$ ). Afterwards, $0.2 \mathrm{~g}$ of magnetic $\mathrm{Fe}_{3} \mathrm{O}_{4}$ nanostructure was dispersed into a mixture of $5 \mathrm{~mL}$ of deionized water and $25 \mathrm{~mL}$ of ethanol using ultrasonic wave, and then $4 \mathrm{~mL}$ of concentrated ammonia (28\%) and $1 \mathrm{~mL}$ of Tetraethyl orthosilicate were added and thoroughly stirred for $15 \mathrm{~min}$ (solution B). Solutions A and B were then admixed and stirred at room temperature for $1.5 \mathrm{~h}$. Following the reaction and exposure of magnet to the solution, the product was separated and rinsed a few times with ethanol and deionized water, respectively. The final $\mathrm{Fe}_{3} \mathrm{O}_{4} @ \mathrm{SiO}_{2}-\mathrm{MDMIP}$ was achieved after sonication and washing by $150 \mathrm{~mL}$ of the acetic acid and methanol $(1: 9, \mathrm{v} / \mathrm{v})$ solution. This process was replicated four times (10 min each run), and the resultant product was dried at $50{ }^{\circ} \mathrm{C}$ (Fu et al., 2019). The preparation of $\mathrm{Fe}_{3} \mathrm{O}_{4} @ \mathrm{SiO}_{2}-\mathrm{MNIP}_{\mathrm{P}}$ was carried out under the same conditions without adding $\mathrm{p}-\mathrm{CA}$ and FA.

\subsection{MDMIP based on SS-MSPME}

In this method, two medical syringes (20 mL, V.MED) were attached together with one metal interface, which was later used as a microextraction flask. Next, the sample solution (10 mL) comprising of $50 \mathrm{ng} \mathrm{mL} \mathrm{m}^{-1}$ of $\mathrm{p}-\mathrm{CA}$ and $50 \mathrm{ng} \mathrm{mL}^{-1}$ of FA was set to the $\mathrm{pH}$ of 6.0 and transferred to the syringe 1. Subsequently, $20 \mathrm{mg}$ of $\mathrm{Fe}_{3} \mathrm{O}_{4} @ \mathrm{SiO}_{2}-\mathrm{MDMIP}$ was added to the syringe 2. Syringe 1 was then connected to syringe 2 , and the sample solution in syringe 1 was rapidly injected into syringe 2 , and vice versa. The two processes were performed in a four-time cycle and within $30 \mathrm{~s}$. By a strong magnet placed outside syringe 1, $\mathrm{Fe}_{3} \mathrm{O}_{4} @ \mathrm{SiO}_{2}-\mathrm{MDMIP}$ was readily separated from the solution, and the supernatant solution was injected into syringe 2. For the elution of $\mathrm{p}-\mathrm{CA}$ and $\mathrm{FA}$, the $\mathrm{Fe}_{3} \mathrm{O}_{4} @ \mathrm{SiO}_{2}-\mathrm{MDMIP}$ was dissolved in $100 \mu \mathrm{L}$ of $\mathrm{MeOH} / \mathrm{AcOH}(9: 1, \mathrm{v} / \mathrm{v})$ using sonication for $1 \mathrm{~min}$ and then separated by a strong magnetic field. In the end, the eluent was transferred to a microtube, and the extract $(20 \mu \mathrm{L})$ was injected into HPLC, to quantify $\mathrm{p}-\mathrm{CA}$ and FA concentration according to the calibration curve for the calculation of extraction percentage. The schematic of the suggested method for the extraction of $p-C A$ and FA is shown in Fig. 1. 


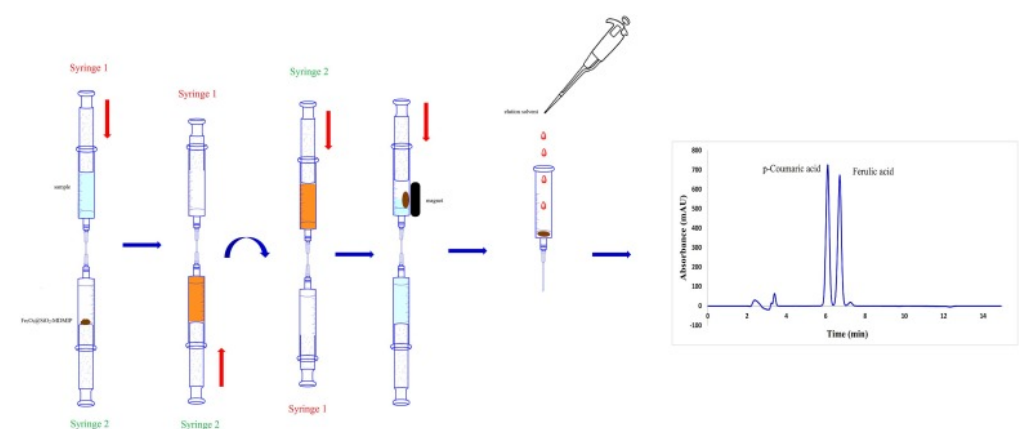

Fig. 1. The schematic of the developed method for the extraction of $p$-CA and FA.

\subsection{Experimental design}

Using STATISTICA 10.0 software, the results of the experimental design, attained by CCD under response surface methodology (RSM), were statistically analyzed. This process was performed to evaluate the optimum conditions of the extraction. The RSM-based CCD allows the experimental conditions to optimize and the number of experiments to minimize. (Karoui et al., 2020) CCD was also used to evaluate the impact of all the studied factors and the interaction between the controlled parameters on the extraction recovery. $\mathrm{pH}(\mathrm{A}), \mathrm{Fe}_{3} \mathrm{O}_{4} @ \mathrm{SiO}_{2}-\mathrm{MDMIP}$ mass (B), $\mathrm{NaCl}$ concentration (C), number of cycle (D), and elution volume (E) are the independent factors included in this study. The ranges of coded levels, independent factors, and dependent responses are shown in Table S1. The dependent responses of $E R_{p-C A} \%$ and $E R_{F A} \%$ were the microextraction recovery of $p-C A$ acid and $F A$, respectively. In addition, analysis of variance (ANOVA) and the determination coefficients are a basis for constructing the semi-empirical model to predict the trend of response over space, which is achieved following the confirmation of the applicability of proposed mathematical quadratic equation that justifies the fitting quality of the experimental data (Jin et al., 2019, Song et al., 2020).

\section{Results and discussion}

\subsection{Characterization of $\mathrm{Fe}_{3} \mathrm{O}_{4}$ and $\mathrm{Fe}_{3} \mathrm{O}_{4} @ \mathrm{SiO}_{2}-\mathrm{MDMIP}$ nanoparticles}

FE-SEM of the $\mathrm{Fe}_{3} \mathrm{O}_{4}$ nanoparticles (Fig. S1a) revealed similar-sized and spherical shape particles, and the TEM evaluation (Fig. S1b) showed nanoparticles with a unified size ranging from 10 to $30 \mathrm{~nm}$. Based on the XRD analysis of $\mathrm{Fe}_{3} \mathrm{O}_{4}$ nanoparticles in Fig. $\mathrm{S} 1 \mathrm{c}$, the peak indicates the intensity of its pure form without any impurity. This outcome was obtained in the result of eight X-ray diffraction peaks at $2 \theta=30.0^{\circ}, 35.6^{\circ}, 37.0^{\circ}, 43.1^{\circ}, 47.0^{\circ}, 53.4^{\circ}, 57.3^{\circ}$ and $62.8^{\circ}$ (JCPDS NO. 88-0866) assigned to the crystal

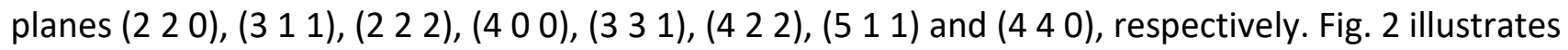
the SEM and TEM images of $\mathrm{Fe}_{3} \mathrm{O}_{4} @ \mathrm{SiO}_{2}-\mathrm{MDMIP}$, which possesses spherical MDMIP with a relatively uniform size and good dispersion. The average particle size of $\mathrm{Fe}_{3} \mathrm{O}_{4} @ \mathrm{SiO}_{2}-\mathrm{MDMIP}$ is approximately $100 \mathrm{~nm}$, while the respective layer is smooth with the thickness of about $15 \mathrm{~nm}$. These results somewhat prove that there is no self-polymer nanostructure in the entire system and justify that the reaction was adequately conducted. 

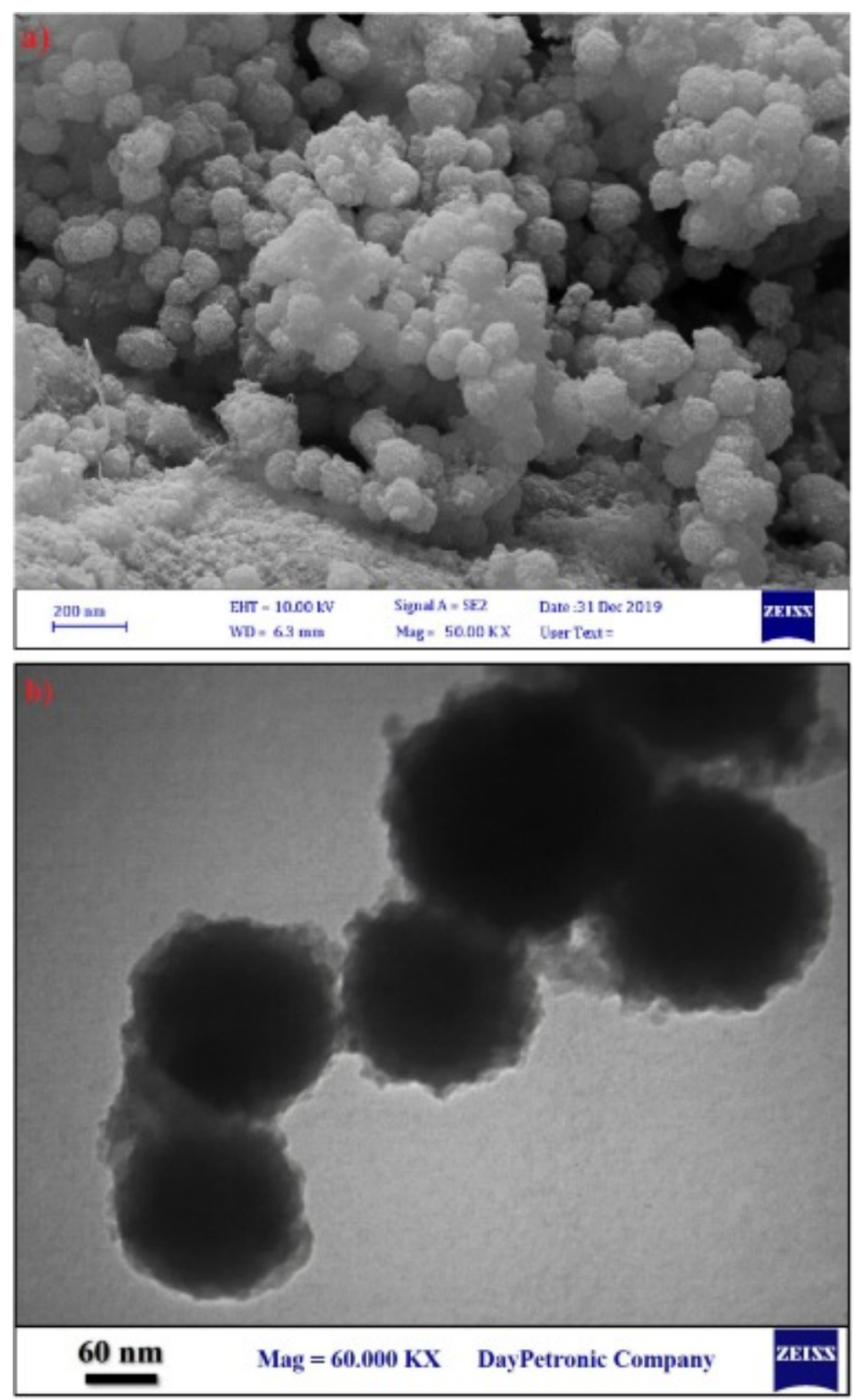

Fig. 2. (a) SEM and (b) TEM images of the $\mathrm{Fe}_{3} \mathrm{O}_{4} @ \mathrm{SiO}_{2}-\mathrm{MDMIP}$.

\subsection{Effect of elution solvent}

In the SS-SPME method, elution is an important step, and elution solvent is an effectual factor in the extraction efficiency. Therefore, elution solvent studied in the present study has to be able to fully desorb the p-CA and FA from the $\mathrm{Fe}_{3} \mathrm{O}_{4} @ \mathrm{SiO}_{2}-\mathrm{MDMIP}$ surface and diminishes the memory effect. To achieve this objective, we used different elution solvents, including $\mathrm{AC}, \mathrm{MeOH}, \mathrm{EtOH}, \mathrm{ACN}$, $\mathrm{MeOH} / \mathrm{AcOH}(9: 1, \mathrm{v} / \mathrm{v}), \mathrm{MeOH} / \mathrm{AcOH}(8: 2, \mathrm{v} / \mathrm{v}), \mathrm{ACN} / \mathrm{MeOH}(50: 50, \mathrm{v} / \mathrm{v})$, and DMSO. The results, as indicated in Fig. S2, suggest that the highest elution performance is obtained when using both $\mathrm{MeOH} / \mathrm{AcOH}(9: 1, \mathrm{v} / \mathrm{v})$ and $\mathrm{MeOH}$. $\mathrm{MeOH} / \mathrm{AcOH}(9: 1, \mathrm{v} / \mathrm{v})$ was also employed as an elution phase because of its better elution and repeatability than $\mathrm{MeOH}$. 


\subsection{Optimization design and analysis}

CCD is an effective method for the optimization of extraction procedures. Therefore, in this research, CCD was utilized to identify the optimal conditions of five factors chosen for $\mathrm{p}-\mathrm{CA}$ and FA determination by SS-SPME and also to measure possible interactions between the factors. The experimental design and dependent responses for $\mathrm{p}$-CA and FA determination are shown in Table S1. Based on the results, the following quadratic equations (Eqs. (1), (2)) were evaluated by ANOVA:(1)ERp-CA\%=+106.3+12.1A-1.9B-56.6C-15.0D-0.01E+0.1AB-4.6AC+0.5AD-0.01AE2.05BC+0.6BD+0.004BE+26.7CD+0.3CE-0.08DE-1.1A2+0.03B2-12.5C2+0.04D2(2)ERFA\% $=+66.7+5.0 \mathrm{~A}-$ $3.6 \mathrm{~B}+1.2 \mathrm{C}+1.5 \mathrm{D}+0.3 \mathrm{AB}-3.6 \mathrm{AC}+0.1 \mathrm{AD}+0.01 \mathrm{AE}-2.9 \mathrm{BC}+1.03 \mathrm{BD}-0.0007 \mathrm{BE}+2.7 \mathrm{CD}+0.2 \mathrm{CE}-0.1 \mathrm{DE}-$ $0.5 \mathrm{~A} 2+0.1 \mathrm{~B} 2+30.3 \mathrm{C} 2-1.0 \mathrm{D} 2-0.001 \mathrm{E} 2$

The results of ANOVA demonstrated high model F-value (96.665 and 116.94 for p-CA and FA, respectively) and low model $P$-value $(<0.001)$. This observation denotes that the two models are significantly appropriate for explaining the extraction of $\mathrm{p}-\mathrm{CA}$ and FA as functions of conditions of the selected variables (Table S2). The lack-of-fit F-values of $3.883(P$-value $=0.079)$ and $1.797(P$ values $=0.268$ ) implies that the lack-of-fit is insignificant relative to the pure error. This insignificant lack-of-fit verifies the favorable predictability of the two models, which can be justified by the excellent linearity between predicted and observed results for the p-CA and FA extraction (Fig. S3). "Adeq precision" is adequate precision and measures the signal-to-noise ratio. A ratio $>4$ is desirable. In our study, the Adeq precision for $p$-CA was 41.888 and for FA was 50.830, reflecting an adequate signal. The goodness of fit of the models was confirmed by the "predicted R" of 0.8882 and 0.9038 and

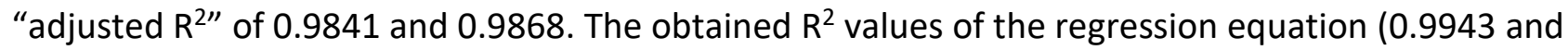
0.9953 ) disclose that the chosen variables can explain $99.43 \%$ of the experimental results for $p-C A$ and 99.53\% for FA.

\subsection{Three-dimensional plots}

The three-dimensional plots of the proposed models, together with the corresponding threedimensional plots (Fig. S4a-f), describe the plot correlation and contribution of two factors while maintaining the other factors at optimum values on the responses. The sample $\mathrm{pH}$ is an important factor controls the nature, charge, and chemistry of analytes and under study sorbent and consequently the limit extent and capacity of $\mathrm{Fe}_{3} \mathrm{O}_{4} @ \mathrm{SiO}_{2}-\mathrm{MDMIP}$ for the extraction of $\mathrm{p}$-CA and FA. As a result, contribution of $\mathrm{pH}$ value (ranged from 2 to 10 ) to the extraction recoveries of $\mathrm{p}$-CA and FA was $>95 \%$ in $\mathrm{pH}$ 6. This result can be attributed to various processes arisen from reaction between hydrogen and polymer materials and also ascribed to the decreased extraction of $\mathrm{p}-\mathrm{CA}$ and FA as a reaction in both acid and base media in the wake of protonation and/or ionization of $p$-CA and FA, which giving rise to the lower hydrogen bond between the two compounds and monomer. The effect of the amount of $\mathrm{Fe}_{3} \mathrm{O}_{4} @ \mathrm{SiO}_{2}-\mathrm{MDMIP}$ on p-CA and FA recoveries revealed that the elevation of $\mathrm{Fe}_{3} \mathrm{O}_{4} @ \mathrm{SiO}_{2}-\mathrm{MDMIP}$ content, from 5 to $20 \mathrm{mg}$, led to unacceptable extraction recoveries, while the content in the range of 20-25 mg had a higher loading/elution of p-CA and FA recoveries, due to their successful extraction. Besides, the effect of ionic strength, via changing $\mathrm{NaCl}$ content in the range of $0.2-1.0 \% \mathrm{w} / \mathrm{v}$, on the efficiency of SS-MSPME technique uncovered that the addition of $\mathrm{NaCl}$ through two opposite phenomena affects the recovery of analytes. The initial increase of $\mathrm{NaCl}$ by salting-out, through lowering solubility, results in the increased extraction, and the enhancement of high $\mathrm{NaCl}$ 
content gives rise to higher viscosity, thereby lowering mass transfer and accordingly diminishing recoveries (Jouyban, Farajzadeh, \& Mogaddam, 2020). In this study, the first effect was stronger than the second one, and as a consequence, raising $\mathrm{NaCl}$ content led to the enhancement of extraction recoveries. The number of injection/back injection cycle had contribution to the extraction recoveries of $\mathrm{p}-\mathrm{CA}$ and $\mathrm{FA}$, because of $\mathrm{Fe}_{3} \mathrm{O}_{4} @ \mathrm{SiO}_{2}-\mathrm{MDMIP}$ sufficient time for contacting with p-CA and FA in samples solution. The profiles of injection/back injection cycle between 1 and 5 cycle(s) revealed a significant change in cycles 1 to 4, showing that the higher number of cycles, the higher extraction recoveries. Additionally, there was no obvious difference in the extraction recoveries at higher number of injection/back injection cycle up to 5 cycles. Accordingly, four injection/back injection cycles were enough to permit the quantitative transfer of p-CA and FA from the bulk solution onto $\mathrm{Fe}_{3} \mathrm{O}_{4} @ \mathrm{SiO}_{2}-$ MDMIP. With regard to the alteration in the eluent volume, we used the minimum volume of the elution, in order to achieve high enrichment factor (EF) and preconcentration factor and simultaneously reduce hazardous problems to the environment and also permit the quantitative recoveries of $\mathrm{p}$-CA and FA. Accordingly, various eluent volumes in the range from 50 to $250 \mu \mathrm{L}$ revealed that lower recoveries at lower eluent volume strongly increase by the elevation of eluent volume, which is logical due to higher dissolubility of p-CA and FA.

\subsection{Optimization conditions}

Figure of merits were determined to achieve the highest extraction of $p-C A$ and FA, and the desirability function was performed by the STATISTICA software. According to the output results, p-CA and FA recoveries could reach the optimum values of $100.00 \%$ and $98.68 \%$ at the following conditions: initial $\mathrm{pH}$ 6, $20 \mathrm{mg}$ of $\mathrm{Fe}_{3} \mathrm{O}_{4} @ \mathrm{SiO}_{2}-\mathrm{MDMIP}, 0.4 \% \mathrm{w} / \mathrm{v}$ of $\mathrm{NaCl}, 4$ cycle injection/back injection, and $100 \mu \mathrm{L}$ of $\mathrm{MeOH} / \mathrm{AcOH}$ (Fig. S5). Validation and real applicability of the suggested optimum point were checked by the replication of some similar experiments at the same conditions and compared based on $t$-test analysis. Accordingly, experimental analyses under optimum factor conditions yielded $97.61 \pm 3.85 \%$ and $94.27 \pm 3.14 \%$ extraction percentage for $p-C A$ and $F A$, respectively.

\subsection{Method validation}

Under the optimized conditions and using the limits of detection (LOD) and quantification (LOQ), linear range, $E F$, and intra-day and inter-day precision (RSD\%), the performance of the proposed method (Table S3) was evaluated. The linear ranges of $p$-CA and FA concentrations and their signal were in the range of $0.5-300 \mathrm{ng} \mathrm{mL}^{-1}$ with $\mathrm{R}^{2}>0.99$ (Fig. 3). Sensitivity of the method was assessed with the LOQs and LODs as fundamental aspects of the validation of the analytical method (Sahebi, Konoz, Ezabadi, Niazi, \& Ahmadi, 2020). The calculations of the LOD and LOQ based on a signal-to-noise ratio of 3 and 10 were 0.08 and $0.3 \mathrm{ng} \mathrm{mL}^{-1}$ for $\mathrm{p}-\mathrm{CA}$ and 0.07 and $0.15 \mathrm{ng} \mathrm{mL}^{-1}$ for FA, respectively. The method accuracy was also examined using the extraction recovery. To evaluate the precision of the proposed method, relative standard deviation (RSD), repeatability (intra-day precision), and reproducibility (inter-day precision) assays were performed. Intra-day precision was evaluated over five replicates of the whole analysis process on the same day. Reproducibility precision was, however, determined with a similar procedure, but the tested samples were analyzed in five consecutive days. Under the optimum conditions, ER\% $\pm R S D \%$ for intra-day repeatability and inter-day reproducibility was $96.47 \pm 2.73$ and $94.61 \pm 3.36$ as well as $95.05 \pm 4.19$ and $94.18 \pm 4.80$ for $p-C A$ and for FA, respectively. The EF based on the ratio between the slopes of the calibration curve after and before the 
preconcentration process was 113.8 for $\mathrm{p}-\mathrm{CA}$ and 104.2 for FA, leading to the preconcentration factor of 100 .

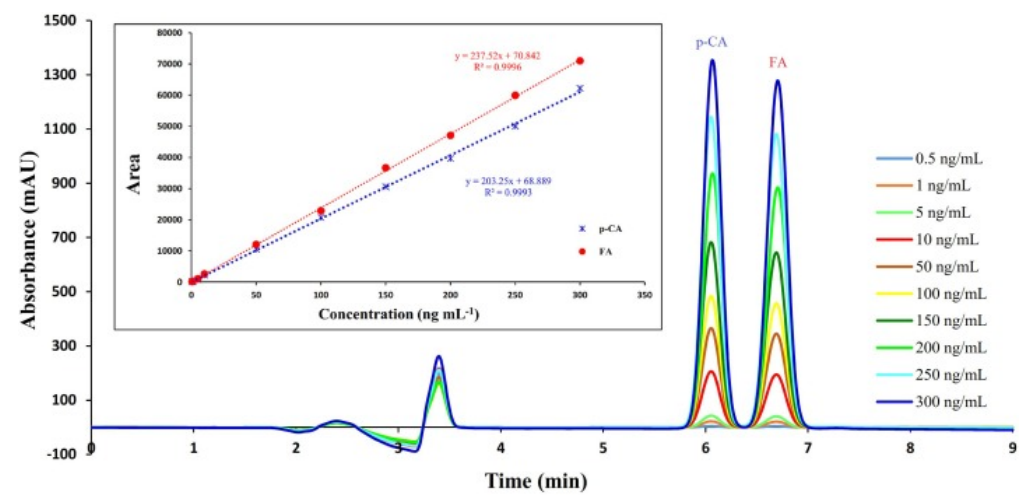

Fig. 3. The chromatogram of linear ranges for $\mathrm{p}-\mathrm{CA}$ and $\mathrm{FA}$ in the range of $0.5-300 \mathrm{ng} \mathrm{mL} \mathrm{L}^{-1}$.

\subsection{Sorption isotherms}

Isotherm models, Langmuir and Freundlich, mainly provide necessary information on and display the mechanism of under study processes, as well as describe the interaction of species with sorbent (Shang et al., 2019). Fig. S6 and Table S4 represent the constants of each model. Based on the largest $\mathrm{R}^{2}$ (>0.99), Freundlich model showed higher ability to fit experimental data for the adsorption of $\mathrm{p}-\mathrm{CA}$ and $\mathrm{FA}$ by $\mathrm{Fe}_{3} \mathrm{O}_{4} @ \mathrm{SiO}_{2}-\mathrm{MDMIP}$. As expected, the adsorption of both species occurred onto the heterogeneous surface of adsorbent. The Freundlich model describes adsorption characteristics for heterogeneous surfaces with good applicability to represent the experimental data (Lima et al., 2019). The favorable adsorption has $1<n<10$ or $0.1<(1 / n)<1$, and the separate and independent process occur at the situation of $n=1$, while the value lower than 1 or higher than 10 strongly confirm its difficultly to occur (Gouthaman, Azarudeen, Gnanaprakasam, Sivakumar, \& Thirumarimurugan, 2018). In addition, the maximum adsorption capacity $\left(q_{\max }\right)$ on $\mathrm{Fe}_{3} \mathrm{O}_{4} @ \mathrm{SiO}_{2}-\mathrm{MDMIP}$, calculated by the Langmuir model, are 52.67 and $47.21 \mathrm{mg} \mathrm{g}^{-1}$ for $\mathrm{p}-\mathrm{CA}$ and FA, respectively. However, the maximum adsorbed amount $\left(q_{\max }\right)$ on $\mathrm{Fe}_{3} \mathrm{O}_{4} @ \mathrm{SiO}_{2}-\mathrm{MNIP}$ for $\mathrm{p}-\mathrm{CA}$ and $\mathrm{FA}\left(17.35\right.$ and $14.05 \mathrm{mg} \mathrm{g}^{-1}$, respectively) is slightly lower than that of the commercial $\mathrm{Fe}_{3} \mathrm{O}_{4} @ \mathrm{SiO}_{2}-\mathrm{MDMIP}$

\subsection{Selectivity investigation}

MIP selectivity against interferents is an advantage. The selectivity highly depends on the specificity of the MIP interactions with the analytes and also geometric factors (Hijazi \& Bottaro, 2019). In our work, selectivity study was carried out using five potential interferents that feature functionalities and or shapes the same as the target analytes. The selectivity experiments were performed by using sinapinic acid (SA), para hydroxybenzoic acid ( $p-H A)$, vanillic acid (VA), gallic acid (GA), and bisphenol A (BA) as the interferences. The interferences were added to $10 \mathrm{~mL}$ of aqueous solution (containing $50 \mathrm{ng} \mathrm{mL}^{-1}$ of $\mathrm{p}-\mathrm{CA}$ and $\mathrm{FA}$ ) at the final concentration of $1000 \mathrm{ng} \mathrm{mL}^{-1}$ with $20 \mathrm{mg}$ of $\mathrm{Fe}_{3} \mathrm{O}_{4} @ \mathrm{SiO}_{2}-$ MDMIP or $\mathrm{Fe}_{3} \mathrm{O}_{4} @ \mathrm{SiO}_{2}-\mathrm{MNIP}$. The binding capacities of $\mathrm{Fe}_{3} \mathrm{O}_{4} @ \mathrm{SiO}_{2}-\mathrm{MDMIP}$ (Table 1) proved that the template molecular imprinted cavity on the surface of $\mathrm{Fe}_{3} \mathrm{O}_{4} @ \mathrm{SiO}_{2}-\mathrm{MDMIP}_{\mathrm{P}}$ has a selective spatial structure. Therefore, $\mathrm{Fe}_{3} \mathrm{O}_{4} @ \mathrm{SiO}_{2}-\mathrm{MDMIP}$ can recognize template molecules that represent selectively. The imprinted factor (IF) and selectivity factor (SF) were also employed to evaluate the selectivity of the MIP according to Eqs. (3), (4) (Li et al., 2019, Zhang et al., 2020).(3)IF =QMIPQNIP(4)SF 
$=$ IFanalytelFiwhere $\mathrm{Q}_{\text {MIP }}$ and $\mathrm{Q}_{\text {NIP }}$ represent the adsorption capacity of $\mathrm{Fe}_{3} \mathrm{O}_{4} @ \mathrm{SiO}_{2}-\mathrm{MDMIP}$ and $\mathrm{Fe}_{3} \mathrm{O}_{4} @ \mathrm{SiO}_{2}-\mathrm{MNIP}$, while $\mathrm{IF}_{\text {analyte }}$ and $\mathrm{IF}_{\mathrm{i}}$ are the imprinting factor for template and analogue, respectively. The data in Table 1 indicate that prepared $\mathrm{Fe}_{3} \mathrm{O}_{4} @ \mathrm{SiO}_{2}-\mathrm{MDMIP}_{\mathrm{P}}$ has great selectivity for $\mathrm{p}$ CA and FA.

Table 1. Imprinting factors (IF) and selectivity factors (SF) of template molecule and analogs for $\mathrm{Fe}_{3} \mathrm{O}_{4} @ \mathrm{SiO}_{2}-\mathrm{MDMIP}$ and $\mathrm{Fe}_{3} \mathrm{O}_{4} @ \mathrm{SiO}_{2}-\mathrm{MNIP}$.

\begin{tabular}{|l|l|l|l|l|l|l|l|l|}
\hline & & p-CA & FA & SA & p-HA & VA & GA & BA \\
\hline$Q_{\text {MDMIP }}\left(\mathrm{mg} \mathrm{g}^{-1}\right)$ & & 52.67 & 47.21 & 18.36 & 15.18 & 14.31 & 10.57 & 4.62 \\
\hline$Q_{\text {MNIP }}\left(\mathrm{mg} \mathrm{g}^{-1}\right)$ & & 17.35 & 14.05 & 17.39 & 14.82 & 14.85 & 9.35 & 5.28 \\
\hline IF & & 3.036 & 3.360 & 1.056 & 1.024 & 0.9636 & 1.130 & 0.875 \\
\hline SF & p-CA & - & - & 2.875 & 2.965 & 3.151 & 2.687 & 3.470 \\
\hline & FA & - & - & 3.182 & 3.281 & 3.487 & 2.9737 & 3.840 \\
\hline
\end{tabular}

\subsection{Application for real samples}

Real applicability of the proposed method was validated following its usage for monitoring the analytes under study in real fruit samples, such as pomegranate (Fig. S7), grape (Fig. S8), and orange (Fig. S9), with regard to known spike value for their complicated matrices (Table 2). As it was expected, reasonable recoveries in the range of $85.12-94.96 \%$ with RSDs $\leq 5.58 \%$ confirm high accuracy and acceptable repeatability of the proposed method for evaluating such analytes in these complicated samples.

Table 2. Application of the developed method for the determination of $p-C A$ and FA in real fruit samples.

\begin{tabular}{|c|c|c|c|c|c|c|c|}
\hline $\begin{array}{l}\text { Real } \\
\text { Samples }\end{array}$ & $\begin{array}{l}\text { Added (ng } \\
m L^{-1} \text { ) }\end{array}$ & $\begin{array}{l}\text { Found (p-CA, } \\
\left.n g L^{-1}\right)\end{array}$ & $\begin{array}{l}\text { Found (FA, } \\
n g \mathrm{~mL}^{-1} \text { ) }\end{array}$ & $\begin{array}{l}\mathbf{R R}_{\mathbf{p}-} \\
\mathrm{CA}^{\mathrm{a}}{ }^{\mathrm{a}}\end{array}$ & $\mathrm{RR}_{\mathrm{FA}} \%$ & $\begin{array}{l}R^{R S D_{p}} \\
\text { CA }(\%)\end{array}$ & $\mathrm{RSD}_{\mathrm{FA}}(\%)$ \\
\hline \multirow[t]{4}{*}{ Pomegranate } & 0 & 3.717 & 9.153 & - & - & - & - \\
\hline & 10 & 12.945 & 18.558 & 92.45 & 94.58 & 2.72 & 3.19 \\
\hline & 100 & 98.635 & 102.693 & 94.96 & 93.59 & 3.30 & 3.64 \\
\hline & 200 & 191.483 & 190.862 & 93.89 & 90.88 & 4.71 & 3.50 \\
\hline \multirow[t]{4}{*}{ Grape } & 0 & 5.341 & 1.925 & - & - & - & - \\
\hline & 10 & 14.249 & 10.718 & 89.49 & 88.18 & 4.82 & 1.77 \\
\hline & 100 & 95.881 & 89.56 & 90.58 & 87.66 & 2.99 & 3.69 \\
\hline & 200 & 182.538 & 172.133 & 88.62 & 85.12 & 4.11 & 3.27 \\
\hline \multirow[t]{4}{*}{ Orange } & 0 & $N^{b}$ & 1.554 & - & - & - & - \\
\hline & 10 & 9.205 & 10.815 & 92.05 & 93.15 & 4.52 & 5.36 \\
\hline & 100 & 89.416 & 91.647 & 89.42 & 90.15 & 5.07 & 5.58 \\
\hline & 200 & 181.542 & 184.903 & 90.77 & 91.70 & 4.21 & 4.79 \\
\hline
\end{tabular}

\footnotetext{
a Relative recovery.
}

a Not detected. 


\subsection{Regeneration of $\mathrm{Fe}_{3} \mathrm{O}_{4} @ \mathrm{SiO}_{2}-\mathrm{MDMIP}$}

The recyclability of $\mathrm{Fe}_{3} \mathrm{O}_{4} @ \mathrm{SiO}_{2}-\mathrm{MDMIP}$ was evaluated by 10-time repetition of SS-MSPME method using the same $\mathrm{Fe}_{3} \mathrm{O}_{4} @ \mathrm{SiO}_{2}-\mathrm{MDMIP}$. As shown in Fig. S10, the extraction efficiency of $\mathrm{Fe}_{3} \mathrm{O}_{4} @ \mathrm{SiO}_{2}-$ MDMIP was still above $90 \%$ for $\mathrm{p}$-CA and above $80 \%$ for FA after five cycles. Based on the results, the synthesized $\mathrm{Fe}_{3} \mathrm{O}_{4} @ \mathrm{SiO}_{2}-\mathrm{MDMIP}$ had excellent stability and ability to enrich both p-CA and FA.

\subsection{Comparison of the proposed method to other relevant methods}

The results of the comparison of the method presented in this study with others are exhibited in Table 3. Our method showed satisfactory LOD and linear response over a wide concentration range for the extraction of p-CA and FA. In virtue of high selectivity and sensitivity, our proposed SS-MSPME method had the best performance for the $\mathrm{p}-\mathrm{CA}$ and FA determination in fruits. The method also was superior to other approaches reported in the literature due to advantages such as short extraction time, low RDS\% values, and acceptable adsorption capacity.

Table 3. Comparison of the characteristic performance data obtained using SS-MSPME with those of other methods for the determination of $\mathrm{p}-\mathrm{CA}$ and FA in real fruit samples.

\begin{tabular}{|c|c|c|c|c|c|}
\hline Analyte & Method & Real Sample & $\begin{array}{l}\text { Linear } \\
\text { Range }\end{array}$ & LOD & Ref. \\
\hline & & & $\left(\mathrm{ng} \mathrm{mL} \mathrm{mL}^{-1}\right)$ & & \\
\hline \multirow[t]{5}{*}{$\mathrm{p}-\mathrm{CA}$} & HPLC-ECD & Citrus honey & $0.35-70$ & 3.20 & $\begin{array}{l}\text { (Liang, Cao, Chen, } \\
\text { Xiao, \& Zheng, 2009) }\end{array}$ \\
\hline & UPLC-MS & Rat plasma & $\begin{array}{l}0.8080- \\
808.0\end{array}$ & 1.05 & (Du et al., 2017) \\
\hline & HPLC-DAD & Malus pumila & $45-4400$ & 9.0 & (Bai et al., 2016) \\
\hline & Fluorescence & Fruit juices & $20-100$ & 6.74 & (Long et al., 2019) \\
\hline & HPLC-UV & $\begin{array}{l}\text { Pomegranate, grape, } \\
\text { and orange }\end{array}$ & $0.5-300$ & 0.08 & Present Work \\
\hline \multirow[t]{6}{*}{ FA } & GC-FID & Honey, wine & $\begin{array}{l}111000- \\
238400\end{array}$ & 3000 & $\begin{array}{l}\text { (Citová, Sladkovský, \& } \\
\text { Solich, 2006) }\end{array}$ \\
\hline & HPLC-DAD & Propolis & $50-49440$ & 11.7 & (Wang et al., 2014) \\
\hline & HPLC-DAD & Fruit juices & $2-500$ & 0.44 & (Saraji \& Ghani, 2014) \\
\hline & $\begin{array}{l}\text { Capillary } \\
\text { electrophoresis }\end{array}$ & Vegetable oils & $100-30000$ & 35 & $\begin{array}{l}\text { (Bakar, Makahleh, \& } \\
\text { Saad, 2012) }\end{array}$ \\
\hline & HPLC-UV & Vegetable oils & $1.30-1000$ & $\begin{array}{l}0.39- \\
0.63\end{array}$ & (Khezeli et al., 2016) \\
\hline & HPLC-UV & $\begin{array}{l}\text { Pomegranate, grape, } \\
\text { and orange }\end{array}$ & $0.5-300$ & 0.07 & Present Work \\
\hline
\end{tabular}

\section{Conclusions}

In the present survey, the selective MDMIP for p-CA and FA was successfully synthesized. The obtained $\mathrm{Fe}_{3} \mathrm{O}_{4} @ \mathrm{SiO}_{2}-\mathrm{MDMIP}$ showed uniform sizes and high selective adsorption capacity for both compounds, which were suitable for the SS-MSPME process, avoiding the defect of template leakage in the sample pretreatment. Our developed method on the basis of SS-MSPME coupled with HPLC-UV indicated good 
recoveries, reproducibility, and high sensitivity for $\mathrm{p}-\mathrm{CA}$ and FA extraction from pomegranate, grapes, and orange samples. The study of interferents demonstrated a good capability for $\mathrm{p}-\mathrm{CA}$ and FA discrimination as the chromatogram peaks of interfering substances were clearly distinct from the $p$-CA and FA peaks.

\section{CRediT authorship contribution statement}

Ebrahim Alipanahpour Dil: Conceptualization, Methodology, Investigation, Formal analysis, Validation, Writing - original draft. Mehrorang Ghaedi: Supervision, Resources, Writing - review \& editing. Arash Asfaram: Formal analysis, Validation, Writing - original draft. Fatemeh Mehrabi: Investigation, Formal analysis, Writing - original draft. Ardeshir Shokrollahi: Validation. Amir Abbas Matin: Validation. Lobat Tayebi: Validation, Writing - review \& editing.

\section{Declaration of Competing Interest}

The authors declare that they have no known competing financial interests or personal relationships that could have appeared to influence the work reported in this paper.

\section{References}

Bai et al., 2016. L. Bai, S. Guo, Q. Liu, X. Cui, X. Zhang, L. Zhang, X. Yang, M. Hou, C.-T. Ho, N. Bai. Characterization of nine polyphenols in fruits of Malus pumila Mill by high-performance liquid chromatography. Journal of Food and Drug Analysis, 24 (2) (2016), pp. 293-298

Bakar et al., 2012. N.B.A. Bakar, A. Makahleh, B. Saad. In-vial liquid-liquid microextraction-capillary electrophoresis method for the determination of phenolic acids in vegetable oils. Analytica Chimica Acta, 742 (2012), pp. 59-66

Cheng et al., 2019. Y. Cheng, J. Nie, J. Li, H. Liu, Z. Yan, L. Kuang. Synthesis and characterization of core-shell magnetic molecularly imprinted polymers for selective recognition and determination of quercetin in apple samples. Food Chemistry, 287 (2019), pp. 100-106

Citová et al., 2006. I. Citová, R. Sladkovský, P. Solich. Analysis of phenolic acids as chloroformate derivatives using solid phase microextraction-gas chromatography. Analytica Chimica Acta, 573-574 (2006), pp. 231-241

Costa et al., 2019. R. Costa, A. Albergamo, S. Arrigo, F. Gentile, G. Dugo. Solid-phase microextractiongas chromatography and ultra-high performance liquid chromatography applied to the characterization of lemon wax, a waste product from citrus industry. Journal of Chromatography A, 1603 (2019), pp. 262-268

Dil et al., 2019 E.A. Dil, A. Asfaram, F. Sadeghfar. Magnetic dispersive micro-solid phase extraction with the CuO/ZnO@ Fe 30 4-CNTs nanocomposite sorbent for the rapid pre-concentration of chlorogenic acid in the medical extract of plants, food, and water samples.

Analyst, 144 (8) (2019), pp. 2684-2695

Dil et al., 2019. E.A. Dil, M. Ghaedi, A. Asfaram. Application of hydrophobic deep eutectic solvent as the carrier for ferrofluid: A novel strategy for pre-concentration and determination of mefenamic acid in human urine samples by high performance liquid chromatography under experimental design optimization. Talanta, 202 (2019), pp. 526-530

Dil et al., 2020. E.A. Dil, M. Ghaedi, A. Asfaram, L. Tayebi, F. Mehrabi. A ferrofluidic hydrophobic deep eutectic solvent for the extraction of doxycycline from urine, blood plasma and milk samples 
prior to its determination by high-performance liquid chromatography-ultraviolet. Journal of Chromatography A, 1613 (2020), Article 460695

Du et al., 2017. Y. Du, Z. Wang, L. Wang, M. Gao, L. Wang, C. Gan, C. Yang. Simultaneous determination of seven phenolic acids in rat plasma using UHPLC-ESI-MS/MS after oral administration of Echinacea purpurea extract. Molecules, 22 (9) (2017), p. 1494

Fu et al., 2019. X. Fu, D. Zhu, L. Huang, X. Yan, S. Liu, C. Wang. Superparamagnetic core-shell dummy template molecularly imprinted polymer for magnetic solid-phase extraction of food additives prior to the determination by HPLC. Microchemical Journal, 150 (2019), Article 104169

Ghorbani et al., 2019. M. Ghorbani, M. Aghamohammadhassan, M. Chamsaz, H. Akhlaghi, T. Pedramrad. Dispersive solid phase microextraction. TrAC Trends in Analytical Chemistry, 118 (2019), pp. 793-809 Gouthaman et al., 2018.

A. Gouthaman, R.S. Azarudeen, A. Gnanaprakasam, V.M. Sivakumar, M. Thirumarimurugan. Polymeric nanocomposites for the removal of Acid red $\mathbf{5 2}$ dye from aqueous solutions: Synthesis, characterization, kinetic and isotherm studies. Ecotoxicology and environmental safety, 160 (2018), pp. 42-51

Hijazi and Bottaro, 2019. H.Y. Hijazi, C.S. Bottaro. Molecularly imprinted polymer thin-film as a microextraction adsorbent for selective determination of trace concentrations of polycyclic aromatic sulfur heterocycles in seawater. Journal of Chromatography A (2019) 460824

Huang et al., 2020. Y. Huang, M. Lu, L. Chen, M. Bai, X. Ouyang, X. Huang. Development of solid-phase microextraction with multiple interactions-based monolithic fibers for the sensitive determination of perfluoroalkyl phosphonic acids in water and vegetable samples. Talanta, 206 (2020), Article 120198

Jin et al., 2019. X. Jin, X. Zhou, P. Sun, S. Lin, W. Cao, Z. Li, W. Liu. Photocatalytic degradation of norfloxacin using $\mathbf{N}$-doped TiO2: Optimization, mechanism, identification of intermediates and toxicity evaluation. Chemosphere, 237 (2019), Article 124433

Jouyban et al., 2020. A. Jouyban, M.A. Farajzadeh, M.R.A. Mogaddam. In matrix formation of deep eutectic solvent used in liquid phase extraction coupled with solidification of organic droplets dispersive liquid-liquid microextraction; application in determination of some pesticides in milk samples. Talanta, 206 (2020), Article 120169

Karoui et al., 2020. S. Karoui, R. Ben Arfi, K. Mougin, A. Ghorbal, A.A. Assadi, A. Amrane. Synthesis of novel biocomposite powder for simultaneous removal of hazardous ciprofloxacin and methylene blue: Central composite design, kinetic and isotherm studies using BrouersSotolongo family models. Journal of Hazardous Materials, 387 (2020), Article 121675

Khezeli et al., 2016. T. Khezeli, A. Daneshfar, R. Sahraei. A green ultrasonic-assisted liquid-liquid microextraction based on deep eutectic solvent for the HPLC-UV determination of ferulic, caffeic and cinnamic acid from olive, almond, sesame and cinnamon oil. Talanta, 150 (2016), pp. 577-585

Li et al., 2019. Z. Li, J. Wang, X. Chen, S. Hu, T. Gong, Q. Xian. A novel molecularly imprinted polymersolid phase extraction method coupled with high performance liquid chromatography tandem mass spectrometry for the determination of nitrosamines in water and beverage samples. Food Chemistry, 292 (2019), pp. 267-274 
Liang et al., 2009. Y. Liang, W. Cao, W.-J. Chen, X.-H. Xiao, J.-B. Zheng. Simultaneous determination of four phenolic components in citrus honey by high performance liquid chromatography using electrochemical detection. Food Chemistry, 114 (4) (2009), pp. 1537-1541

Lima et al., 2019. V.V.C. Lima, F.B. Dalla Nora, E.C. Peres, G.S. Reis, É.C. Lima, M.L.S. Oliveira, G.L. Dotto. Synthesis and characterization of biopolymers functionalized with APTES (3aminopropyltriethoxysilane) for the adsorption of sunset yellow dye. Journal of Environmental Chemical Engineering, 7 (5) (2019), Article 103410

Long et al., 2019. R. Long, T. Li, C. Tong, L. Wu, S. Shi. Molecularly imprinted polymers coated CdTe quantum dots with controllable particle size for fluorescent determination of p-coumaric acid. Talanta, 196 (2019), pp. 579-584

Moradi et al., 2019. Z. Moradi, E.A. Dil, A. Asfaram. Dispersive micro-solid phase extraction based on Fe $304 @$ SiO2@ TI-MOF as a magnetic nanocomposite sorbent for the trace analysis of caffeic acid in the medical extracts of plants and water samples prior to hplc-uv analysis. Analyst, 144 (14) (2019), pp. 4351-4361

Nosrati et al., 2018. H. Nosrati, N. Sefidi, A. Sharafi, H. Danafar, H.K. Manjili. Bovine serum albumin (BSA) coated iron oxide magnetic nanoparticles as biocompatible carriers for curcuminanticancer drug. Bioorganic Chemistry, 76 (2018), pp. 501-509

Pang et al., 2019. J. Pang, Y. Liao, X. Huang, Z. Ye, D. Yuan. Metal-organic framework-monolith composite-based in-tube solid phase microextraction on-line coupled to high-performance liquid chromatography-fluorescence detection for the highly sensitive monitoring of fluoroquinolones in water and food samples. Talanta, 199 (2019), pp. 499-506

Rahimi et al., 2019. M. Rahimi, S. Bahar, R. Heydari, S.M. Amininasab. Determination of quercetin using a molecularly imprinted polymer as solid-phase microextraction sorbent and highperformance liquid chromatography. Microchemical Journal, 148 (2019), pp. 433-441

Rozaini et al., 2019. M.N.H. Rozaini, N.-

F. Semail, B. Saad, S. Kamaruzaman, W.N. Abdullah, N.A. Rahim, ..., N. Yahaya. Molecularly imprinted silica gel incorporated with agarose polymer matrix as mixed matrix membrane for separation and preconcentration of sulfonamide antibiotics in water samples. Talanta, 199 (2019), pp. 522-531

Sahebi et al., 2020. H. Sahebi, E. Konoz, A. Ezabadi, A. Niazi, S.H. Ahmadi. Simultaneous determination of five penicillins in milk using a new ionic liquid-modified magnetic nanoparticle based dispersive micro-solid phase extraction followed by ultra-performance liquid chromatography-tandem mass spectrometry. Microchemical Journal, 154 (2020), Article 104605

Saraji and Ghani, 2014. M. Saraji, M. Ghani. Dissolvable layered double hydroxide coated magnetic nanoparticles for extraction followed by high performance liquid chromatography for the determination of phenolic acids in fruit juices. Journal of Chromatography A, 1366 (2014), pp. 24-30

Shang et al., 2019. Y. Shang, Y. Cui, R. Shi, P. Yang, J. Wang, Y. Wang. Regenerated WO2.72 nanowires with superb fast and selective adsorption for cationic dye: Kinetics, isotherm, thermodynamics, mechanism. Journal of Hazardous Materials, 379 (2019), Article 120834 
Song et al., 2020. W. Song, J. Li, Z. Wang, C. Fu, X. Zhang, J. Feng, ..., Q. Song. Degradation of bisphenol A by persulfate coupled with dithionite: Optimization using response surface methodology and pathway. Science of the Total Environment, 699 (2020), Article 134258

Wang et al., 2014. Z. Wang, R. Sun, Y. Wang, N. Li, L. Lei, X. Yang, ..., H. Zhang. Determination of phenolic acids and flavonoids in raw propolis by silica-supported ionic liquid-based matrix solid phase dispersion extraction high performance liquid chromatography-diode array detection. Journal of Chromatography B, 969 (2014), pp. 205-212

Zhang et al., 2020. Y. Zhang, D. Liu, J. Peng, Y. Cui, Y. Shi, H. He. Magnetic hyperbranched molecularly imprinted polymers for selective enrichment and determination of zearalenone in wheat proceeded by HPLC-DAD analysis. Talanta, 209 (2020), Article 120555 